\title{
University Traveler Value of Potential Real-Time Transit Information
}

\author{
Ryan N. Fries \\ Southern Illinois University \\ Anne E. Dunning and Mashrur A. Chowdhury \\ Clemson University
}

\begin{abstract}
Intelligent transportation systems (ITS) have become common in public transit systems, particularly providing real-time transit information. For new implementations, it remains difficult to predict and quantify system and user benefits of technology implementation. Although previous studies have quantified the operational benefits of real-time transit traveler information systems, a gap in knowledge exists around passenger benefits of such systems. The objective of this research was to create a refined method for evaluating transit rider benefits from real-time traveler information and predict changes in traveler behavior. The study was conducted on a rural university campus, isolating the impacts of the system from the multiple influences that often affect transportation in larger metropolitan areas. This study uniquely integrated transit system performance, pedestrian travel times, and traffic simulation to determine travel times and predict mode split. Findings indicated that reducing passenger waiting anxiety was the most significant measure of traveler benefit from such a system. While the benefits found were specific to the study site, the methodology can be used for other transit systems evaluating real-time transit technology investments in rural or urban environments.
\end{abstract}




\section{Introduction}

Intelligent transportation systems (ITS) are used to improve transportation quality and efficiency through the integrated use of communications and technologies, but anticipating the effect of technology investment in the multimodal and multifaceted transportation system is daunting. Within the scope of ITS, advanced public transportation systems (APTS) focus on public transit, and the Federal Transit Administration has invested significant research funding in this area since the mid1990s. Past research has endeavored to capture the effects of traveler information on transit operations, traveler wait time, and willingness to ride. In many cases, the research involved examining a change in one variable, such as attractiveness of transit, without examining corresponding changes in the transportation system, such as more transit riders leaving space on the road for more vehicles. An examination of the impact of APTS on the full transportation system is needed to provide a true predictive tool for the impacts of ITS investment.

The objective of this research was to create a refined method for evaluating transit rider benefits from real-time transit information (RTTI) and predict changes in traveler behavior. This study was conducted to quantify the benefit that a proposed automatic vehicle location (AVL) and transit traveler information system could provide to transit riders. The real-time traveler information system was anticipated to provide pretrip information via the Internet and enroute information on displays at key transit stops. The new method incorporates the simulation of traffic and the stochastic estimation of pedestrian travel times as modes competing with the transit system performance. The results of this method can provide decision makers with information about the potential value of advanced public transportation systems to passengers in smaller communities and university campuses.

\section{Previous Research into the Impacts of ITS}

Designers of RTTI systems have aimed to streamline management of operations and provide benefits for riders. This section describes the current state of knowledge on the impacts of real-time transit traveler information.

\section{System Benefits}

Previous studies on RTTI significantly focused on improving operational efficiency through vehicle allocation (Crawford 2010) and other management means (Pangilinan et al. 2008; Khattak and Hickman 1998; Law et al. 1998; Nace and McKay 1997; Kontaratos et al. 1996), but not particularly on the user benefit of such systems. 
The following subsections indicate research findings on the impacts to individual travelers.

\section{Ridership Generation}

As a primary system benefit for public transit, ridership generation has received much research attention. The factors found to increase the use of a new service, such as a new route or stop, have included younger riders, frequent riders, riders without a car, and the presence of riders closer to the new service than to existing (Chatterjee and Ma 2007). The ridership influence from RTTI appeared in the results of a 2002 intercept survey of 928 tourists and local residents riding the Island Explorer system serving Acadia National Park and surrounding communities on Mount Desert Island in Maine. In this study, 85 percent of bus riders surveyed said real-time information relieved uncertainty about when the bus would get to the stop, and 80 percent of bus riders surveyed said real-time information helped them decide to use the bus. The statement "I would plan to use this information if visiting in the next 12 months" met with agreement from 92 percent of the users (Zimmerman et al. 2004). This latter study indicated both a system benefit of generating ridership and a user benefit of time savings.

\section{Mode Shift}

The behavioral factors surrounding a traveler's tendency to shift modes away from personal vehicles also has been frequently studied. Throughout the world, programs have begun to encourage car drivers to explore new modes of transportation such as transit, walking, or biking (Jones 2003; Cairns et al. 2004; Brog 1998; Department of Transport 2000; Ampt and Rooney 1999; Rose and Ampt 2001; Taniguchi et al. 2002; Taniguchi et al. 2003). These encouragements typically increased awareness of travel alternatives through marketing and are generally termed travel feedback programs. These programs have induced reductions in car use between 7 and 19 percent in Australia, the European Union (Jones 2003), and Japan (Fujii and Taniguchi 2006). Most recently, Taniguchi and Fujii found that little difference exists between the benefits of diverse types of travel feedback programs and that travel feedback programs were the most effective method of changing travel behavior because they impacted either the behavioral intentions or the implementation intentions of travelers (Taniguchi and Fujii 2007). These findings suggest that although travel behaviors are difficult to change, particularly with travelers who habitually use automobiles, a travel feedback program has the most potential to encourage less personal car use, compared to other methods. Specifically, provid- 
ing RTTI can provide a part of a traveler feedback program, thereby playing a role in discouraging personal vehicle usage and encouraging transit ridership.

\section{Traveler Information and User Benefits}

The following subsections indicate research findings on the impacts to individual travelers.

\section{In-Vehicle Travel Time}

Various research areas have related to the value of in-vehicle transit travel time. Some have evaluated the impact of traveler multitasking on the value of their travel time-for example, talking on the phone while riding on the bus. The researchers of one study hypothesized that because travelers viewed long waits and travel times negatively and because multitasking can make these times seem shorter or at least more pleasurable and useful, then multitasking can make the perceived cost of travel and wait times lower. Through a stated-preference survey of over 200 Dutch travelers in the Eindhoven region, researchers found that riders who enjoy multitasking perceive the time cost of their travel 32 percent lower than those who prefer to sit and wait for or on transit vehicles (Ettema and Verschurne 2007).

Intelligent transportation systems have a small role, at best, in encouraging multitasking to reduce the perceived cost of in-vehicle travel time. On-board announcements of upcoming stops can help alert multitasking people who would otherwise feel the need to focus on watching out the window for landmarks. Even so, a stronger benefit to real-time information lies in the potential to reduce the cost/utility of time that travelers spend waiting for a transit vehicle to arrive.

\section{Out-of-Vehicle Wait Time}

Several studies have focused on real-time information for transit riders. One such study used numerical methods and focused on the importance of capturing the wait time of those passengers that miss a bus due to its early arrival compared to the schedule. The findings suggested that as the standard deviation of bus arrival increases, information systems should predict that buses will arrive earlier than expected, thus reducing the number of passengers who "just miss" a bus (Chien et al. 2006).

Other studies have focused on measuring the reduction of perceived wait time when RTTI is provided, finding a wide range of results. Wardman (2003) used a face-to-face survey, finding that between 21 and 65 percent of riders perceived a shorter wait time with RTTI. Kronborg et al. (2002) found that although travelers using RTTI still overestimated their wait time (9-13\%), those without arrival infor- 
mation perceived wait time even longer (overestimating 24-30\%). Further studies in London and the Netherlands found that providing RTTI reduced the perception of wait time by 26 percent (Schweiger 2003) and 20 percent (Dziekan and Kottenhoff 2007), respectively. While these studies identify a range of overestimation for urban transit riders, none focuses on the unique population of a college campus.

Mishalani et al. (2006) recently examined the difference between perceived and actual bus rider wait times at stops on and around the Ohio State University campus, finding that for bus headways between 3 and 15 minutes, riders perceived their wait time approximately 15 percent longer than it actually was (Mishalani et al. 2006), providing a foundation for the study described in this article.

Another study has investigated the perception of transit riders towards the value of real-time information. The findings of this work suggested that while the expected ridership increases are modest, passengers put enormous value on "... knowing when the next bus will arrive ...[] knowing how long the delay is ...[, and] improving on-time performance" (Peng et al. 2002). While no quantifications of these values were undertaken in this study, subsequent work has evaluated the impact of AVL on schedule performance, discovering that on-time performance can be improved by such systems (Pangilinan et al. 2008).

These last studies lend themselves back to the works discussed earlier. As individual travel experience improves, ridership improves. User benefit and system benefit are closely linked. Also, the previously-mentioned Island Explorer survey findings pose that traveler information might directly improve the user experience by helping riders save time.

\section{Summation of the Literature Review}

As presented, the most decisive findings of advanced public transportation systems have focused on operational efficiency benefits of real-time transit information, not on user benefits. User benefits have been described qualitatively (multitasking as a preferred activity) or quantified through rider surveys, yet surveys have shown that perceptions of wait time inaccurately reflect actual wait times.

When decision makers are considering investing in intelligent transportation systems, they need an objective way to evaluate costs and benefits. This study sought to quantify user benefits of real-time transit information. 


\section{Methodology}

As identified in the introduction, the objective of this research was to create a refined method for evaluating transit rider benefits from real-time traveler information and predict changes in traveler behavior. This method uniquely integrates transit system performance, pedestrian travel times, and traffic simulation to determine travel times and predict mode split. Figure 1 depicts the method developed. The next subsections detail the implementation of this procedure.

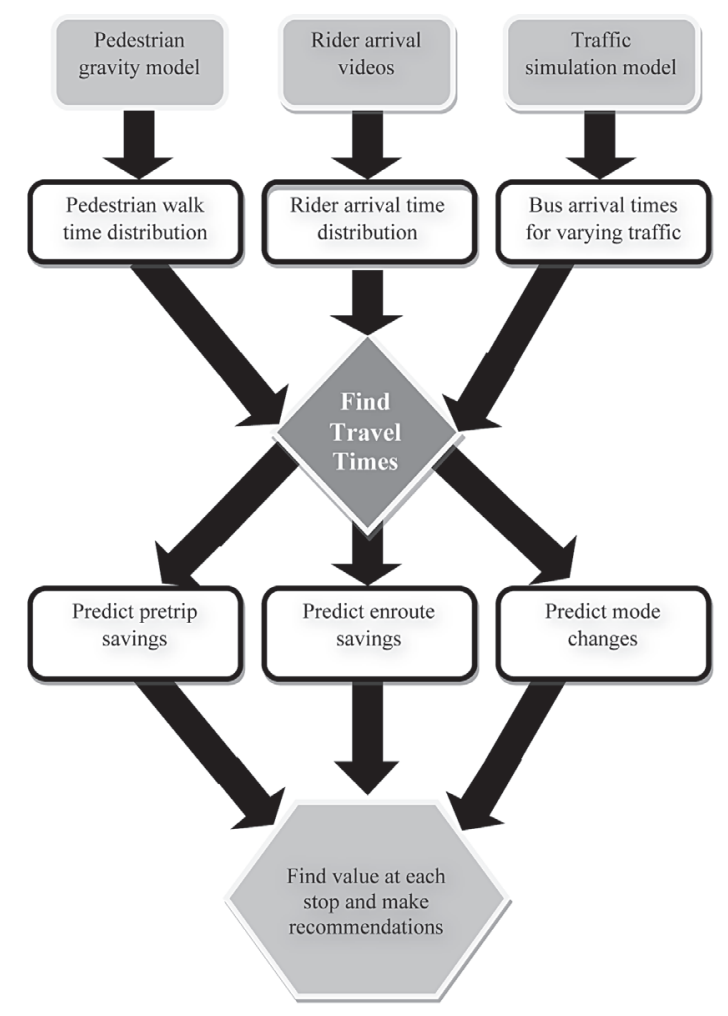

\section{Figure 1. Process for quantifying the effects of} real-time transit Information.

Clemson Area Transit (CAT) served as the test system for this study. Located in rural South Carolina (Figure 2), this bus system has operated as the only public transit serving Clemson University and the cities of Clemson, Seneca, Central, and Pendleton. CAT served a 2009 year-round residential population of 13,002 in Clemson and university enrollment of 19,111 (Table 1). CAT ridership for 2009 was reported at 1.4 million (Howard 2010). 


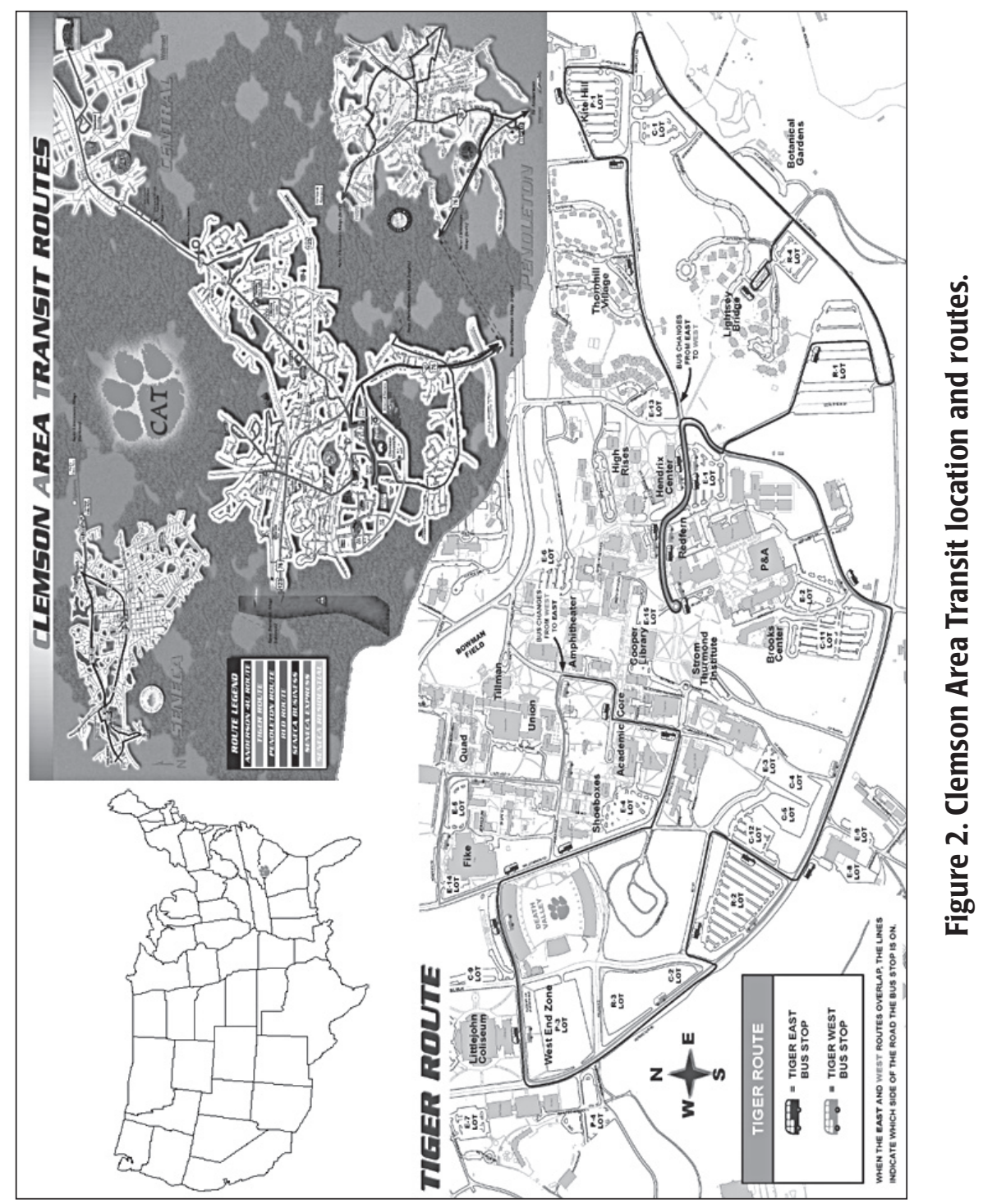


Table 1. 2009 Estimated Local Populations and Student Enrollments Served

\begin{tabular}{|l|c|}
\hline & $\begin{array}{c}\mathbf{2 0 0 9} \\
\text { Estimate }\end{array}$ \\
\hline City of Clemson & 13,002 \\
\hline City of Seneca & 7,832 \\
\hline Town of Central & 4,079 \\
\hline Town of Pendleton & 3,153 \\
\hline Clemson University & 19,111 \\
\hline Tri-County Technical College & 6,758 \\
\hline
\end{tabular}

Sources: U.S. Census Bureau, Clemson University Fact Book, Tri-County Technical College "At a Glance."

The rural and small-town environment in which CAT operates provides an ideal scenario for isolating transportation impacts because many factors are controlled. Travel alternatives such as taxis and overlapping transit routes are relatively nonexistent. Roads are uncongested, which eliminates routine delay as a contributing factor to outcomes. Also, CAT is a well-performing system; it has been recognized as a national leader for generating the highest ridership of a fare-free municipal transit system (Miller 2001).

CAT has not yet deployed ITS technology, so the system provides a base case for research at a time when service facilitation through technology makes sense. System management is investigating feasible ways to implement a prototype AVL system on buses and methods for disseminating this information. Management has expressed interest in communicating this information to passengers via displays at key stops and on the Internet. At the start of this research project, finding the value of a transit real-time information system by measuring user benefit was of great importance to CAT and Clemson University.

\section{Find Travel Times}

Travel times included walking time to the transit stop, wait time at the stop, travel time on the bus, and walking time to the final destination. The following sections detail how these times were estimated.

\section{Gravity Model Development for Pedestrian Walk Times}

To determine the location to which each transit passenger would likely walk on campus, a gravity model was built. Initially, an AutoCAD file of the entire campus was used, and a coordinate system was set around each stop in the study area. 
The locations of nearby campus buildings, such as dorms, labs, and classrooms, were identified in the AutoCAD file. Next, the number of students residing in each dorm was determined, and the number of credit hours offered was calculated for key campus classroom buildings. Last, data from a 2005 on-campus travel pattern survey (Adams et al. 2005) was used to estimate that 60 percent of all bus travelers were going to class and 10 percent were going to their residence. The remaining 30 percent were traveling to other destinations such as shopping or eating. Using this information, researchers divided the transit riders between the class and residence destinations surrounding each campus bus stop. Because Eom et al. (2010) found that student registration is directly comparable to campus building activity level, the gravity for classroom buildings was determined using the number of contact hours in each building. Contact hours were calculated by multiplying the number of students per class by the number of credit hours for each class and summing the products for all of a building's classes. For example, if a particular building had only one three-credit class, with 10 students, the building's gravity would be represented by 30 contact hours ( 3 credits $x 10$ students). The researchers logically neglected buildings that were closer to other bus stops along each route, assuming travelers would find the fastest combination of transit and walking trips to reach their destination. The average gravity for classrooms was determined using Equation 1, where $x$ denotes the east-west distance ( $\mathrm{ft}$ ) from the bus stop, $y$ denotes the north south distance $\left(\mathrm{ft}\right.$ ) from the bus stops, and $C_{h}$ represents contact hours. Similarly, for determining the gravity of residence locations nearby campus bus stops, Equation 2 was used where $x$ and $y$ are defined above, and $R$ denotes the number of residents living at each location, for example, the Clemson House dormitory.

$$
\begin{aligned}
& \boldsymbol{G}_{\text {class }}(x, y)=\left(\frac{\sum x * \boldsymbol{C}_{\boldsymbol{h}}}{\sum \boldsymbol{C}_{\boldsymbol{h}}}, \frac{\sum \boldsymbol{y} * \boldsymbol{C}_{\boldsymbol{h}}}{\sum \boldsymbol{C}_{\boldsymbol{h}}}\right) \\
& \boldsymbol{G}_{\text {residence }}(\boldsymbol{x}, \boldsymbol{y})=\left(\frac{\sum \boldsymbol{x} * \boldsymbol{R}}{\sum \boldsymbol{R}}, \frac{\sum \boldsymbol{y} * \boldsymbol{R}}{\sum \boldsymbol{R}}\right)
\end{aligned}
$$

To finish developing the pedestrian gravity model, the results from equations 1 and 2 were again weighted using the aforementioned ridership data; therefore, the gravity from class buildings was more significant than those from residence buildings. The gravity model was used to determine a representative walking distance and location that transit riders would access from each stop. These equations assume that pedestrians are familiar with the area, choose rather linear routes, and have no significant (larger than a building) obstacles to/from their bus stop and building. 
After identifying these locations, representative walking times were collected for key bus stops and between certain bus stops. These walk times were used to create a normal distribution of walk times for each bus stop.

\section{Transit Rider Arrivals and Wait Times}

Passenger arrival rates have been studied frequently, and there is consensus that for headways greater than 10-12 minutes, the arrival distribution is not random (Csikos and Currie 2008). Although others have approximated arrivals with respect to headways (Luethi et al. 2007), there exist multiple models from around the world. The availability of video data at the study sites allowed the authors to observe transit rider arrivals in the study network from $10 \mathrm{AM}$ to $2 \mathrm{PM}$ (peak campus occupation), and calculate their wait time. During the observation, the bus arrival headway was consistent, and the authors assumed negligible impacts to the arrival distribution measured. Passenger arrivals did not follow the smooth bell shape of a normal distribution; instead, they more closely followed an exponential distribution, as shown in Figure 3. In addition to the normal and exponential distributions, the authors also examined the Weibull, Poisson, and lognormal distributions for goodness of fit, finding the exponential slightly better than the Weibull distribution, as shown in Table 2. This similarity is no coincidence because the Weibull distribution is merely a special case of the more-general exponential distribution.

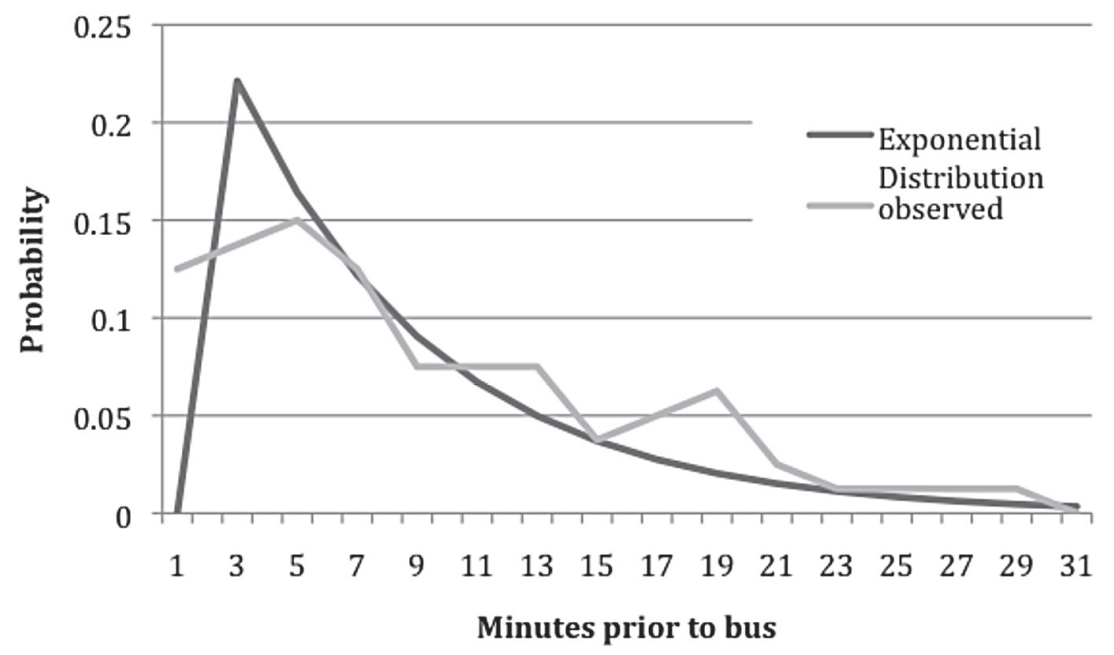

Figure 3. Passenger arrival probability distribution for Red Route bus stops (Fries et al. 2009). 
Table 2. Distributions' Goodness of Fit to Passenger Arrival

\begin{tabular}{|l|c|}
\hline Distribution & Goodness of Fit $\left(\mathbf{r}^{2}\right)$ \\
\hline Normal & 0.572 \\
\hline Poisson & 0.383 \\
\hline Lognormal & -0.823 \\
\hline Weibull & 0.779 \\
\hline Exponential & 0.780 \\
\hline
\end{tabular}

Researchers also examined the activities of those awaiting bus arrival. Findings suggest that 54 percent of waiting travelers multitask. To allow the applicability of previous research (Ettema and Verschurne 2007), multitasking was considered as participating in any task while waiting for the bus. Because multitasking can decrease the time-cost of waiting for a bus, this factor was used to determine an appropriate time value.

Three different bus routes were examined in this analysis (Red, Blue, Pendleton), and the scheduled headways are displayed in Table 3. Passenger arrival data were collected for Red route (30-minute headways) passengers, and the passengers arriving at stops for the Pendleton route (60-minute headways) were assumed to follow the same distribution of arrival because both routes have long enough headways to cause travelers to plan their arrival at the transit stop. Thus, it was assumed that riders of both routes would arrive approximately 5 minutes before the bus and rarely arrive more than 10 minutes prior. Because of the Blue route's short headways (5.7 minutes), riders would not likely refer to schedules and were assumed to arrive randomly (McLeod 2007).

Table 3. Scheduled and Observed Bus Headways

\begin{tabular}{|l|c|c|c|c|}
\hline Bus Route & $\begin{array}{c}\text { Scheduled } \\
\text { Headways } \\
\text { (mins) }\end{array}$ & $\begin{array}{c}\text { Observed Avg. } \\
\text { Headway } \\
\text { (mins) }\end{array}$ & $\begin{array}{c}\text { Standard } \\
\text { Deviation } \\
\text { (mins) }\end{array}$ & $\begin{array}{c}\text { Error }(E) \text { for } \\
\text { 95\% Confidence } \\
\text { (mins) }\end{array}$ \\
\hline Red & 30 & 29.7 & 2.1 & 0.7 \\
\hline Blue & 6 & 5.7 & 1.6 & 0.4 \\
\hline Pendleton & 60 & 59.8 & 3.1 & 1.8 \\
\hline
\end{tabular}

\section{Bus Arrival Distributions}

Bus arrival distributions were collected from video data similar to passenger wait times and, in some cases, during the same viewing. To increase the number of observations, bus headways also were used from videos containing no stops by 
recording the frequency a certain bus passed by, assuming it would arrive at stops with roughly the same headway and variance. The aggregated data for these bus arrivals is shown in Table 3. Note that the average headway of each bus has been captured with $95 \%$ confidence and an error that was no more than three percent of the headway (maximum found for Pendleton route).

\section{Travel Time Calculation}

After finding the characteristics of walk times, rider wait times, and bus headways, the travel times were found. To account for the variable nature of transportation network demand and travel times, particularly for transit vehicles without dedicated rights-of-way, a traffic simulation model was used. The model was built using VISSIM and included approximated 13,000 links, over 700 parking lots, and 12 traffic signals around campus. Because multiple routes were available between each origin and destination, a dynamic assignment approach was taken to model the background traffic. Further, multiple classes of vehicles were defined to mimic the parking restriction differences between faculty and staff, students, visitors, local residents, and university vehicles. This model was extensively calibrated and validated as described in Fries et al. (2010). Calibration included checking volumes, adjusting link costs, verifying signal operations, and comparing travel times, then adjusting driver characteristics until travel times were within one percent of observed. The validation included verifying volumes were within one percent of observed, comparing travel speeds, and conducting face-validation, a visual comparison of the simulated traffic and the observed daily traffic.

CAT operates eight transit routes: Orange Route, Red Route (eastbound and westbound), Blue Route, Pendleton Route, Central Maverick Route, Seneca Express Route, Anderson Route, and Lightsey Bridge Route. These routes serviced 29 stops in the model and, while several routes may service the same stops, passenger loads were modeled uniquely for each line according to the 2007 Ridership Count Survey (Connectics 2007). Dwell times were not specified; instead, dwell times were determined based on the number of passengers observed to either board or alight at a stop.

The simulation model also was used to quantify the impact of varying traffic demands. Seven scenarios were simulated, each representing a different percent of the average traffic demand, including 50, 75, 100 (base scenario), 125, 150, 175, and 200 percent. During these simulations, the average travel times were recorded for buses and private vehicles (considered as all vehicles other than buses). 
Summing the total travel time for transit riders, a random number generator selected 100 walk times to each bus stop based on a normal distribution from the collected data. Next, another random number generator selected 100 wait times from an exponential distribution developed from the observed wait time data. After that, 100 bus travel times were found from the simulation model using the base scenario (100\% traffic demand). Last, 100 samples were taken randomly from a normal distribution of walk times from the destination stop. Adding each sample together provided 100 stochastic travel times for each pair of origins and destinations selected. For example, one traveler on the Red route took 5.1 minutes to walk to the bus stop, waited 2.1 minutes for the bus to arrive, spent 9.8 minutes on the bus, and walked an additional 2.4 minutes to reach his/her final destination, therefore spending 19.5 minutes traveling. Authors reviewed the data to ensure that the riders reducing their travel time by using pre-trip information did not benefit also from reduced utility for that same time (that he/she would have been at the bus stop), thereby preventing the model from counting the same benefited time twice.

\section{Quantifying Impacts}

The impacts sought in this research were in four categories: pre-trip time savings, en-route time value, mode change savings, and impact of varying traffic. The preceding paragraphs discuss how these impacts were determined.

One way that travelers can benefit from transit real-time information would be planning their arrival at stops. The methodology for this analysis referred to the Intelligent Transportation Systems Deployment Analysis Software (IDAS) to determine that in 2008, approximately nine percent of transit travelers in the U.S. will use pre-trip travel information to better-plan their trip (McTrans, Inc. 2003). Due to the prevalence of tech-savvy students on and around a college campus, this assumption is conservative. Because pre-trip information will benefit only those who would have arrived at the bus stop excessively early, compared to arrival of the bus, this approach assumed that those who were planning to arrive at the stop earlier-than-average (5.2 minutes prior to the Red bus) would instead arrive at that average time. Because not all travelers will have an opportunity to save time using pre-trip information, the time savings were averaged over all 100 travelers, where a value of zero was noted for those travelers who could not save any time using pretrip information. Using this overall savings - for example, 0.5 minutes - and applying it to the nine percent of riders who might use such a service, the total time savings was estimated. 
To quantify the time savings into dollars, IDAS was again referenced. Applying the recommended inflation rate of 3 percent to the 1995 values of transit traveler time and accounting for the observed multitasking, the 2008 time values were found as $\$ 19.96 /$ hour. This cost was determined from the IDAS estimation of \$24.14 (2008) and accounting for those multitasking ( $54 \%$ observed), valuing their time 32 percent less (Ettema and Verschurne 2007). While other works have explored the non-linear value of waiting time (Denuit and Genest 2001; Osuna 1985), many assumptions were required to fit a value curve to travel times at Clemson, and this analysis was considered beyond the scope of this study. The benefit for pre-trip traveler information is considered solely as time saved by passengers waiting at the bus stop less.

The proposed system was not being evaluated for operational improvements, again making the estimate conservative. Instead, the benefits were taken from the reduction of passenger anxiety/utility, reducing the uncertainty and thus the utility of the time, while awaiting a bus. Various studies have confirmed that travelers are uneasy waiting for buses and perceive time to be longer than it actually is (Dziekan and Kottenhoff 2007; Schweiger 2003; Nijkamp et al. 1996). One study on a college campus was the most applicable to the study site, finding that awaiting passengers perceived their wait time 15 percent higher than it actually was (Mishalani et al. 2006). In quantifying the benefits, the perceived 15 percent extra wait time is considered the savings because of the reduced uncertainty of passengers and is valued at $\$ 19.96 /$ hour for CAT passengers, as previously discussed. For example, a particular passenger arrived at her stop 2.1 minutes prior to the bus, perceived her wait as 2.4 minutes, and could have reduced the utility of her wait type by 0.3 minutes if she knew when the bus was arriving.

Between certain on-campus origins and destinations, providing real-time bus arrival data could encourage would-be riders to walk instead, to save time. The walk time distributions to and from the centroid of each bus stop area were taken from the previous data collected and compared to the predicted travel time including waiting, riding on the bus, and walking from the bus stop. After finding the percentage of riders that had an opportunity to save time by walking, a sensitivity analysis was conducted to predict the savings under different passenger decision conditions. For example, the analysis sought the benefits if all passengers walked if they could save time doing so. Because various factors influence mode choice, developing a model such as a logit model was beyond the scope of this analysis.

Because traffic is ever-increasing in the Clemson area, and it is unclear when the proposed transit traveler information system will be implemented, an examination 
of traffic variation was conducted. The procedure simply compared the change in private vehicle travel time with the change of transit travel time, attempting to identify the volume at which private vehicle travel time increases significantly more than transit vehicles due to parking space searches.

\section{Findings}

Enroute savings was the most significant benefit of the proposed system, particularly at locations with high ridership, such as the P1 parking lot. Mode change represented the least benefit from the proposed system. Table 4 and Figure 4 show the anticipated benefits if the proposed system were fully operational and if different numbers of passengers decide to change mode because of the bus arrival data. The column titled "Possible Riders Shifting" displays the number of riders per day that might save time if they decided to walk instead of waiting for the next bus. Because it is not likely that all riders will decide to change modes to save time, the table illustrates the value if different percentages of riders are willing to shift modes to save themselves travel time. These findings indicate little financial benefit for riders to shift modes, supporting previous work by Hickmann and Wilson (1995).

Table 4. Daily Mode Change Findings

\begin{tabular}{|l|c|c|c|}
\hline Origin & Destination & $\begin{array}{c}\text { Avg Time Savings } \\
\text { (mins) }\end{array}$ & $\begin{array}{c}\text { Possible Riders } \\
\text { Shifting }\end{array}$ \\
\hline Sikes Hall & Hendrix Center & 3.73 & 8 \\
\hline Hendrix Center & Lot P1 & 0.10 & 70 \\
\hline Lot P1 & Hendrix Center & 0.06 & 6 \\
\hline
\end{tabular}

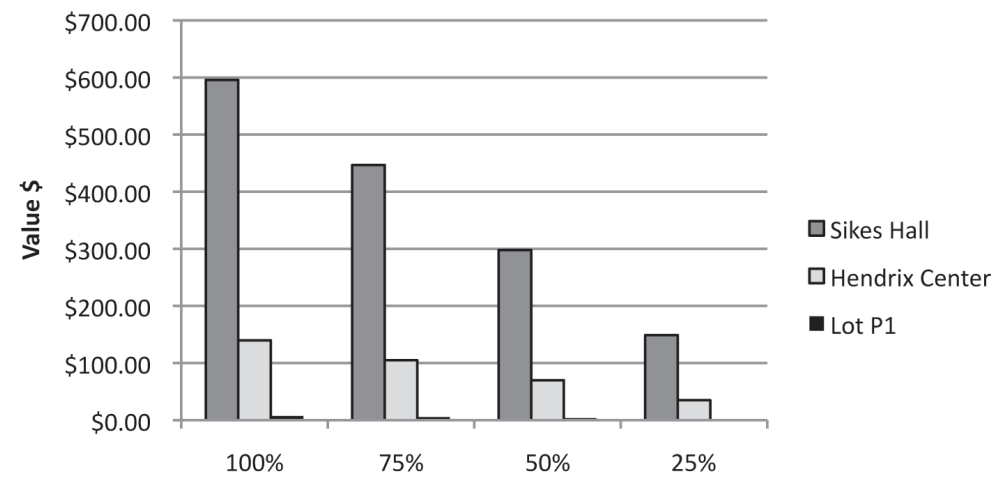

Figure 4. Daily mode shift value. 
Table 5 shows the compiled results from all three of these benefits areas. Note that the mode change value was used at the 50-percent level and was not found for most sites because walking between the origin and destination was not reasonable. The annual values were determined accounting for only the Fall and Spring semesters of normal operation. Also, the total does not add benefits of anxiety reduction and mode shift because both reduce the same wait time (at the same value) and their addition would incorrectly count a portion of saved travel time.

Table 5. Transit Real-time Information System Benefits per Stop

\begin{tabular}{|l|c|c|c|c|c|c|}
\hline \multirow{2}{*}{ Bus Stop } & Route(s) & $\begin{array}{c}\text { Value Per Day (Weekday) } \\
\text { Reduction }\end{array}$ & $\begin{array}{c}\text { Pretrip } \\
\text { Savings }\end{array}$ & $\begin{array}{c}\text { Mode Shift } \\
\text { Savings }\end{array}$ & Total & $\begin{array}{c}\text { Annual } \\
\text { Value }\end{array}$ \\
\hline Lot P1 & Blue & $\$ 2,592$ & - & $\$ 5$ & $\$ 2,592$ & $\$ 414,745$ \\
\hline $\begin{array}{l}\text { E. Library } \\
\text { Circle }\end{array}$ & $\begin{array}{c}\text { Blue, } \\
\text { Pendleton }\end{array}$ & $\$ 2,158$ & $\$ 41$ & - & $\$ 2,197$ & $\$ 351,508$ \\
\hline $\begin{array}{l}\text { Hendrix } \\
\text { Center }\end{array}$ & Red, Blue & $\$ 852$ & $\$ 72$ & $\$ 105$ & $\$ 924$ & $\$ 147,773$ \\
\hline Sikes Hall & Red & $\$ 387$ & $\$ 103$ & $\$ 447$ & $\$ 489$ & $\$ 78,319$ \\
\hline Lemans & Red & $\$ 424$ & $\$ 86$ & - & $\$ 510$ & $\$ 81,626$ \\
\hline $\begin{array}{l}\text { University } \\
\text { Village }\end{array}$ & Red & $\$ 222$ & $\$ 67$ & - & $\$ 289$ & $\$ 46,178$ \\
\hline $\begin{array}{l}\text { Tri-County } \\
\text { Tech }\end{array}$ & Pendleton & $\$ 94$ & $\$ 27$ & - & $\$ 122$ & $\$ 19,447$ \\
\hline $\begin{array}{l}\text { Tigertown } \\
\text { Village }\end{array}$ & Pendleton & $\$ 31$ & $\$ 12$ & - & $\$ 43$ & $\$ 6,879$ \\
\hline
\end{tabular}

The true value of such a system is likely much higher than found by this conservative estimate. For one, operational improvements of the bus system, though welldocumented elsewhere, were not the focus of this analysis and were not included in the benefits. Second, the percent using the pre-trip data is conservative. Students at a university campus present a unique population to transportation system designers. Because students are increasingly tech-savvy, the proportion of students who would use such a service could be significantly higher than the national average, as specified by IDAS. Further, the availability of computers and networking on campus provides a fertile environment for the growth of pre-trip traveler information. In this study, pre-trip travel was valued for only those stops where users would walk to from their origin (i.e., home or class), not from commuter lots where another mode would have influenced departure time. In these cases, the core value of the real-time information, for example, at lot P1, would be making the wait time more pleasurable and, therefore, less costly. It 
also should be noted that the small urban area in which Clemson University is located does not encounter as much travel time variability as the areas around larger cities.

This analysis did not include the impact of information error such as predicting an incorrect bus arrival time. Other transit traveler information systems, such as Next Bus in and around Washington, D.C., have provided prediction accuracy of over 90 percent (WMATA 2007), and prediction accuracy was found to increase as the transit vehicle nears a stop (Lin and Bertini 2002); therefore, information error was not considered as a significant factor impacting the utility of waiting riders.

Another interesting finding of this study was the impact of changing traffic volumes on the travel times of buses versus personal vehicles. As Figure 5 shows, private vehicle travel times change as significantly as transit vehicle travel times as future traffic volumes grow. While transit travel times increase with heavier road volumes, the total network travel delay is more significantly impacted by private vehicles than transit vehicles due to their numbers. As heavier road volumes can delay transit vehicles, real-time transit information can quell the anxiety of awaiting passengers, and increased personal vehicle travel times has the potential to shift more travelers towards riding transit.

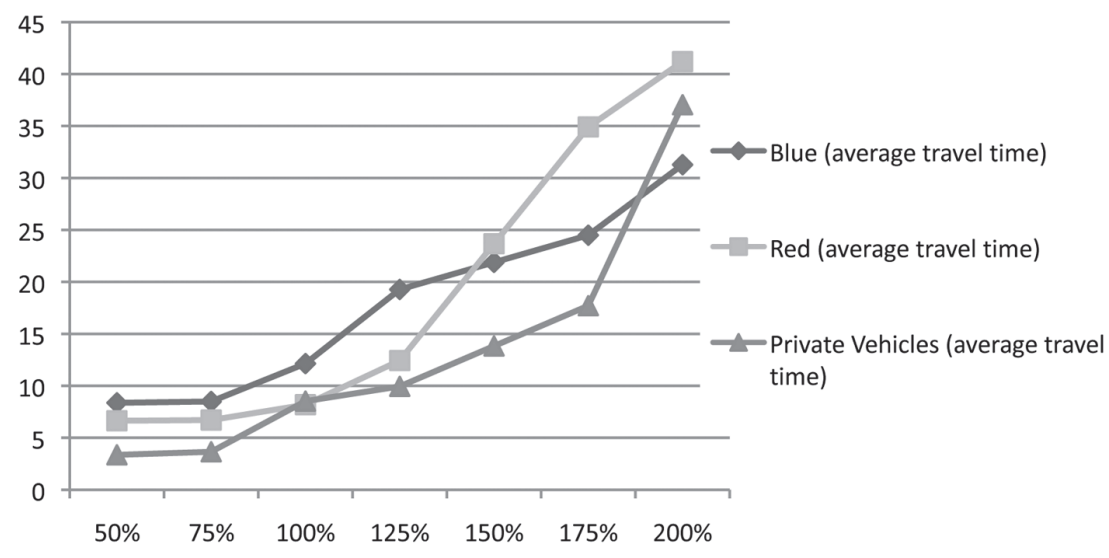

Figure 5. Travel time changes compared to ADT changes (Fries et al. 2009).

\section{Conclusion}

The most significant benefit of real-time transit information was reducing the utility of rider wait time at a stop. Specifically, reducing the anxiety level of waiting passengers was found to be the largest category of benefits to riders. Transit information provided 
over the Internet can save riders waiting time at a transit stop, and the information provided to riders at a bus stop reduces the utility of that wait time. These two tools complement each other, first, possibly by saving travelers time at the stop, and next by making the true time at the stop more useful and less inopportune. Because both of these tools benefit individual riders, larger ridership creates more significant benefits; thus, ridership was the most significant factor influencing the studied benefits.

This study also investigated if real-time transit traveler information would encourage mode shift away from transit and towards walking across campus. Multiple factors influence mode change, in addition to pre-trip information and information provided at bus stops. These include weather, fitness of the rider, disabilities, familiarity with the area, trip chaining, and cargo to carry. Due to these considerations, the mode change savings found were not considered significant between walking and riding the bus; therefore, researchers do not anticipate this tool will significantly decrease the mode share of college campus transit but could encourage students to walk when buses are late.

Other agencies can use the methods presented in this study to examine similar applications on urban transit systems. Operators of college campus transit systems can use the findings of this study to help justify appropriate expenditures on realtime transit traveler information.

Future research should identify what proportion of commuters would shift towards bus and away from personal vehicles because of real-time transit information because the shift between private vehicles and transit has the potential to impact the transportation systems on multiple levels. Additionally, incorporating a non-linear value of travel time and developing a Logit model for mode-split at Clemson can provide further detail to these findings.

\section{Acknowledgments}

Clemson University Parking Services provided support for this research, and Clemson Area Transit allowed access for data gathering and development of the project.

\section{References}

Adams, S., B. Boyles, M. Brown, E. Comstock, A. Dunning. 2005. Clemson University Travel Patterns Preliminary Findings. Clemson, SC: Clemson University Administrative Council, December. 
Ampt, E., and A. Rooney. 1999. Reducing the impact of the car - A sustainable approach, travel smart adelaide. Presented at 23rd Australasian Transport Forum, Perth Australia, Sept. 29-Oct. 1.

Brög, W. 1998. Individualized marketing: Implications for TDM. Presented at the Transportation Research Board of the National Academies Annual Meeting, Washington, D.C., January.

Cairns, S., L. Sloman, C. Newson, J. Anable, A. Kikbride, and P. Goodwin. 2004. Smarter choices: Changing the way we travel. United Kingdom: Department for Transport.

Chatterjee, K., and K.-R Ma. 2007. Modeling the timing of user reponses to a new urban public transport service. Transportation Research Record 2010: 62-72.

Chien, S. I-J., S. K. Daripally, and K. Kim. 2006. Development of a probabilistic model to optimize disseminated real-time bus arrival information for pre-trip passengers. Journal of Advanced Transportation 41:2: 195-215.

Clemson University. 2010. Factbook. http://www.clemson.edu/oirweb1/FB/factbook/minifactbook.cgi

Crawford, D. 2006. New voices: Chicago pioneers passenger information initiatives. ITS International 16(4): 28-29.

Connectics Transportation Group, Inc. 2007. Clemson Area Transit (CAT Bus) ridership counts and analysis. Atlanta, GA: Connectics.

Csikos, D., and G. Currie. 2008. Investigating consistency in transit passenger arrivals insights from longitudinal automated fare collection data. Transportation Research Record 2042: 12-19.

Denuit, M., and C. Genest. 2001. An extension of Osuna's model for stress caused by waiting. Journal of Mathematical Psychology 45: 115-130.

Department of Transport. 2000. Travel Smart: A cost-effective contribution to transport infrastructure. Western Australia: Department of Transport.

Dziekan, K., and K. Kottenhoff. 2007. Dynamic at-stop real-time information displays for public transport: effects on customers. Transportation Research Part A: Policy and Practice 41(6): 489-501.

Eom, J. K., J. R. Stone, and K. Kang. 2010. Empirical cast study of spatial temporal student activity population. Transportation Research Record 2157(2): 11-21. 
Ettema, D. L. and Verschurne. 2007. Multitasking and value of travel time savings. Transportation Research Record 2010: 19-25.

Fries, R., M. Chowdhury, A. Dunning, and M. Reisi-Gahrooei. 2010. Evaluating realtime parking information: Case study of an isolated university campus. Transportation Research Record (in press).

Fries, R., A. Dunning, and M. Chowdhury. 2009. Traveler's value of real-time transit information. Proceedings of the Transportation Research Board Annual Meeting, Washington, D.C., January.

Fujii, S. and A. Taniguchi. 2006. Determinants of the effectiveness of travel feedback programs - A review of communicative mobility management measures for changing travel behavior in Japan. Transport Policy 13:5: 339-348.

Howard, , J. C. 2010. CAT thrives in poor economy. Anderson Independent Mail, Scripps Interactive Newspapers Group. http://www.independentmail.com/ news/2010/sep/07/cat-thrives-poor-economy/.

Jones, P. 2003. Encouraging behavioural change through marketing and management: what can be achieved? Presented at 10th International Conference on Travel Behavior Research, Lucerne, Switzerland.

Khattak, A, J., and M. Hickman. 1998. Automatic vehicle location and computeraided dispatch systems design and application considerations. Journal of Public Transportation 2:1.

Kontaratos, M., V. Balis, and C. Liapakis. 1996. GPS-based AVL system: A tool for supporting public transport operation in the urban area. Presented at the Third World Congress on Intelligent Transportation Systems.

Law, M., J. D. Nelson, and M. G. H Bell. 1998. Modelling of cell-based AVL for improving bus services. Proc. Third IMA International Conference on Mathematics in Transport Planning and Control, Elsevier.

Lin, W.-H., and R. L. Bertini. 2002. Modeling schedule recovery processes in transit operations for bus arrival time prediction. Presented at the IEEE 5th International Conference on Intelligent Transportation Systems, Singapore, September.

Luethi, M., U. A. Weidmann, and A. Nash. 2007. Passenger arrival rates at public transport stations. Presented at 86th Annual Meeting of the Transportation Research Board, Washington, D.C. 
McLeod, F. 2007. Estimating bus passenger waiting times from incomplete bus arrivals data. Journal of the Operational Research Society 58: 1518-1525.

McTrans, Inc. 2003. Intelligent Transportation Systems Deployment Analysis Software.

Miller, J. H. 2001. Synthesis 39: Transportation on college university campuses, a synthesis of transit practice. Washington, D.C: National Academy Press.

Mishalani, R. G., M. M. McCord, and J. Wirtz. 2006. Passenger wait time perceptions at bus stops: Empirical results and impact on evaluating real-time bus arrival information. Journal of Public Transportation 9:2: 89-106.

Nace, B. A. and K. McKay. 1997. Benefits of GPS based automatic vehicle location for fleet management and improved transit operations. Proc. 1997 APTA Bus Operations, Technology, and Management Conference. APTA.

Nijkamp, P., G. Pepping, and D. Banister. 1996. Telematics and Transport Behaviour, Chapter 7: Public transit information systems: An English case study. Heidelburg: Springer.

Osuna, E. E. 1985. The psychological cost of waiting. Journal of Mathematical Psychology 29(82): 105.

Pangilinan, C. A., N. W. Wilson, and A. Moore. 2008. Bus supervision deployment strategies and use of real-time automated vehicle location for improved bus service reliability. Transportation Research Record 2063: 28-33.

Peng, Z.-R., D. Yu, and E. Beimborn. 2002. Transit user perception of the benefits of automatic vehicle location. Transportation Research Record 1791: 127-133.

Rose, G., and E. Ampt. 2001. Travel Blending: An Australian travel awareness initiative. Transportation Research Part D 6: 95-110.

Schweiger, C. L. 2003. Customer and media reactions to real-time bus arrival information systems. Transportation Research Board Report No. 48.

Taniguchi, A., F. Hara, S. Takano, S. and Kagaya. 2002. Study of Traffic environment awareness among elementary schoolers in Japan and a program to raise it. Presented at the 3rd International Conference on Traffic and Transportation Studies, Reston VA. 
Taniguchi, A., and S. Fujii. 2007. Process model of voluntary travel behavior modification and effects of travel feedback programs. Transportation Research Record 2010: 45-52.

Taniguchi, A., F. Hara., S. Takano, S. Kagaya, and S. Fujii. 2003. Psychological and behavioral effects of travel feedback program for travel behavior modification. Transportation Research Record 1839: 182-190.

Tri-County Technical College. October 8, 2010. Tri-County Technical College "At a Glance." <http://www.tctc.edu/Content/Documents/atGlance.pdf>

U.S. Census Bureau. 2010. Population Finder. November. http://www.census.gov/

Warman, P. 2003. Measured impacts of real-time control and information systems for bus services. Transport Direct, UK Department for Transport.

Washington Metropolitan Area Transit Authority. 2007. Next Bus real-time information expanded for Metrobus riders. May 2. http://www.wmata.com/about/ met_news/PressReleaseDetail.cfm?Release ID $=1624 \&$ string=\&PrintFriendly=Y.

Zimmerman, C., J. J. Daigle, and J. Pol. 2004. Tourism business and intelligent transportation systems: Acadia National Park, Maine. Transportation Research Record 1895: 182-187.

\section{About the Authors}

RYAN FrIES, Ph. D., P.E. (rfries@siue.edu) is an Assistant Professor of Civil Engineering at Southern Illinois University, Edwardsville. His specialties include incident management, transportation security, and intelligent transportation systems.

AnNe Dunning, Ph.D. (anned@clemson.edu) is an Associate Professor in the Department of Planning and Landscape Architecture at Clemson University. Her primary research areas include transportation planning, particularly as they relate to public transportation, travel patterns, and evacuation.

MAshrur (Ronnie) Chowdhury, Ph.D., P.E. (mac@clemson.edu) is an Associate Professor in the Department of Civil Engineering at Clemson University. His primary research areas include intelligent transportation systems and transportation security. 